\title{
SARS-CoV-2 spike protein-induced platelet activation: Mechanism for virus and vaccine- induced thrombotic thrombocytopenia
}

Huong Nguyen ( $\sim$ Thi-Huong.Nguyen@iba-heiligenstadt.de )

Iba Heiligenstadt

\section{Li-Yu Chen}

Institute for Bioprocessing and Analytical Measurement Techniques (iba)

Nida Khan

Institute for Bioprocessing and Analytical Measurement Techniques (iba)

Annerose Lindenbauer

Institut für Bioprozess- und Analysenmesstechnik (Iba)

Van-Chien Bui

3Department of Water Supply and Wastewater Treatment, Eichsfeldwerke GmbH

https://orcid.org/0000-0003-2652-4454

\section{Peter Zipfel}

Leibniz Institute for Natural Product Research and Infection Biology https://orcid.org/0000-0002-6149-

2411

Doris Heinrich

Institute for Bioprocessing and Analytical Measurement Techniques (iba)

\section{Article}

Keywords: SARS-CoV-2, COVID-19, VITT, vaccines, platelet activation

Posted Date: August 17th, 2021

DOl: https://doi.org/10.21203/rs.3.rs-746765/v1

License: (c) (i) This work is licensed under a Creative Commons Attribution 4.0 International License.

Read Full License 


\title{
SARS-CoV-2 spike protein-induced platelet activation:
}

\section{Mechanism for virus and vaccine-induced thrombotic thrombocytopenia}

\author{
Thi-Huong Nguyen, ${ }^{1,2, \dagger *}$ Li-Yu Chen, ${ }^{1,3 \dagger}$ Nida Zaman Khan, ${ }^{1,2}$ Annerose Lindenbauer, ${ }^{1}$ \\ Van-Chien Bui, ${ }^{4}$ Peter F. Zipfel, ${ }^{3}$ and Doris Heinrich ${ }^{1,2,5}$ \\ ${ }^{1}$ Institute for Bioprocessing and Analytical Measurement Techniques (iba), Heiligenstadt, Germany \\ ${ }^{2}$ Institute for Chemistry and Biotechnology, Faculty of Mathematics and Natural Sciences, Technische \\ Universität Ilmenau, Ilmenau, Germany \\ ${ }^{3}$ Institute of Microbiology, Friedrich Schiller University, Jena, Germany \\ ${ }^{4}$ Department of Water Supply and Wastewater Treatment, Eichsfeldwerke GmbH, Heilbad \\ Heiligenstadt, Germany \\ ${ }^{5}$ Fraunhofer Institut für Silicatforschung, Neunerplatz, Würzburg, Germany \\ Equal contribution
}

Word count abstract: 250

Word count main text: 3342 (including main text, excluding methods and Figure legends)

Tables: 0

Figures: 7 in the main text; 2 in the supplementary information

References: 60

Corresponding authors:

Dr. Thi Huong Nguyen

Institute for Bioprocessing and Analytical Measurement Techniques (iba)

Rosenhof 1

37308 Heilbad Heiligenstad

Germany

Tel: $+49(0) 3606671600$

E-mails: thi-huong.nguyen@iba-heiligenstadt.de 


\section{Abstract}

Covid-19 pandemic stimulated an extremely fast development of effective vaccines. Recent studies found platelet-activating antibodies against platelet factor 4 (PF4) in both clinically ill Covid-19 patients and vaccine-induced thrombotic thrombocytopenia (VITT) patients. Here, we use various tools to identify the binding reaction of the SARS-CoV-2 spike glycoprotein (SP) with PF4 that results in immunogenic platelet-activating PF4/SP complexes. This binding is evidenced by an increase in mass, optical intensity, and stable binding force observed by quartz crystal microbalance, enzyme immune assay, and force spectroscopy, respectively. The SP induced an increase in the size of PF4 and switched the surface zeta potential of the PF4 from positive to negative values as evaluated by dynamic light scattering. The SP-induced platelet aggregation was identified by functional assay and flow cytometry but in a concentration-dependent manner. Our results indicated that the formed PF4/SP complexes can, on one hand, trigger the formation of PF4-antibodies and on the other hand mediate/activate platelets followed by inducing thrombotic events, which is the mechanism for excessive procoagulant activity observed in Covid-19 patients. With vector-based vaccines, we suggest that soluble SP are produced during the transcription process, forming antigenic PF4/SP complexes that result in a high rate of clotting effects in vaccinated individuals with Ad26.COV2.S and ChAdOx1nCoV-19 vaccines. An additional consideration of PF4/SP complexes in the current guidelines for the diagnosis of VITT will improve the treatment in patients. Our results serve a high demand to develop an effective method to treat Covid-19 patients and improve the safety for Covid-19 vaccination. 


\section{Introduction}

The covid-19 pandemic caused to date (July 24, 2021) 195 million infected cases and $\sim 4.2$ million deaths globally. ${ }^{1,2}$ Hospitalized Covid-19 patients are at risk for developing thrombotic complications such as stroke, limb ischemia, or venous thromboembolism. ${ }^{3}$ The incidence of thromboembolism in patients with severe pneumonia, who have a high risk of inhospital mortality, ${ }^{4}$ is about $25 \% .{ }^{5}$ Abnormal coagulation profiles were observed in $~ 71.4 \%$ of the deaths. ${ }^{6}$ Heparins are recommended for the management of coagulopathy even at higher/double doses, ${ }^{7}$ as they appear to be associated with a better prognosis. ${ }^{8}$ However, heparin-induced thrombocytopenia (HIT) antibodies were confirmed in severe Covid-19 patients. ${ }^{9-12}$ HIT antibodies are developed due to immune response (especially by B lymphocytes) to antigenic complexes, formed between the positively charged chemokine platelet factor 4 (PF4, CXCL4) and negatively charged heparin (H). ${ }^{13}$ These human antibodies cross-link and activate platelets, monocytes, and neutrophils, and bind to endothelial cells (EC) through PF4/H complexes, causing life-threatening complications. ${ }^{14}$ These antibodies contain a platelet-activating Fc $\gamma$ RIIa receptor that induced procoagulant platelets. ${ }^{15}$ The typical HIT antibodies recognize only PF4/H complexes while PF4-autoantibodies interact with both PF4 alone and PF4/H complexes, causing platelet activations. ${ }^{15}$ The incidence of HIT in Covid-19 patients at the intensive care unit is higher $(1.16 \%)$ than for critically ill patients without Covid-19 (0.18\%). ${ }^{16}$

To fight against the pandemic, different types of Covid-19 vaccines have been widely administered. ${ }^{17-18}$ However, individuals exposed to the incorporated replication-incompetent adenoviral vector vaccine (ChAdOx1 nCoV-19, AstraZeneca) developed PF4-antibodies, which activated platelets, causing thrombotic thrombocytopenia. ${ }^{19-23}$ Exposed entities to the mRNA vaccines (BNT162b2, mRNA-1273) also suffered from this side effect, ${ }^{24-25}$ but with a lower rate than the above vaccines. ${ }^{26}$ Although platelet-activating PF4-antibodies have been 
detected in both Covid-19 patients and vaccinated individuals, the mechanism of the development of these antibodies has not yet been elucidated. In general, the inflammatory state and the activation of the coagulation cascade play a role in the development of plateletactivating antibodies.

The SARS-CoV-2 spike protein plays a key role in the receptor recognition and cell membrane fusion process, composing of $S_{1}$ and $S_{2}$ subunits. ${ }^{27}$ The virus binds initially to the cellular receptor angiotensin-converting enzyme 2 (ACE2) through the $\mathrm{S}_{1}$ subunit to get entry into cells. ${ }^{28-29}$ After binding, the virus promotes the fusion of its remaining $\mathrm{S}_{2}$ subunit to undergo large-scale conformational rearrangements. This process leads to an exposure of the hydrophobic fusion peptide on the $\mathrm{S}_{2}$ subunit to fuse the viral into cellular membranes. ${ }^{30}$ It is proposed that the positively charged amino acids of the $S_{1}$ binding region promote the virus fusion with the host. In contrast, the $\mathrm{S}_{2}$ subunit includes amino acids that exhibit a mixture of not only negatively and positively charged residues but also hydrophobic and hydrophilic regions, in which hydrophobic and hydrophilic surfaces are dominant. ${ }^{31}$ In the meanwhile, the plasma-derived purified PF4 protein has a ring of positively charged residues which enable it to bind electrostatically to different molecules, resulting in clear pro-inflammatory properties in vivo. ${ }^{32}$ Healthy donor's sera contain less than $0.5 \mu \mathrm{g} / \mathrm{ml}$ PF4 but PF4 plasma levels are strongly increased up to $30 \mu \mathrm{g} / \mathrm{ml}$ in both severe and non-severe Covid-19 patients. ${ }^{33}$ High concentration of PF4 enhances binding of HIT antibodies. ${ }^{34} \mathrm{PF} 4$ binds strongly to the negatively charged polyanions, ${ }^{35}$ extracellular glycosaminoglycans (GAGs) on platelets, ${ }^{14}$ and heparan sulfate on endothelial cells, ${ }^{36-37}$ inhibiting local antithrombin (AT) activity and thus promoting coagulation.

Based on protein characteristics, we hypothesize that SARS-CoV-2 spike protein subunit 2 (SP) clusters the PF4, forming immunogenic complexes that trigger the immune 
cells, especially B-cells to secrete platelet-activating PF4-antibodies in some patients who had rare biological characteristics, leading to thrombotic thrombocytopenia.

Here, we proved that the SP clusters PF4 by using multiple nanobiophysical and analytical methods. Dynamic light scattering (DLS) was used to track the change in the size and zeta potential of PF4 caused by SP whereas Quartz crystal microbalance (QCM) was applied to track mass change due to the binding of SP to PF4. Single-molecule force spectroscopy (SMFS) based atomic force microscopy was used to identify the binding force of the interactions while Enzyme-linked immunosorbent assay (ELISA) was used to confirm binding on a 96-well plate. We found that the SP clustered PF4 and switched the surface zeta potential of the resulting complexes to negative values and the maximal size of PF4/SP complexes was gained only at a narrow range of PF4:SP concentration. Importantly, SP strongly induced platelet aggregation as tested in functional HIT assays and visualized by confocal laser microscopy (CLSM). SP-induced platelet activation was identified by flow cytometry. Based on these results and recent findings, we propose a mechanism in which the resulting antigenic PF4/SP complexes promote immune B-cells to producing plateletactivating PF4-antibodies that can massively induce platelet aggregation/activation. This explains the unusual clotting disorders in both Covid-19 patients and vaccinated individuals.

\section{Methods}

\section{Ethics}

The use of blood obtained from healthy volunteers was approved by the ethics board of Thüringen.

\section{Reagents}


The following reagents were used: SARS-CoV-2 spike proteins $S_{2}$ subunit, purity $>90 \%$ (SP, MW = 115 kDa, Sheep Fc-Tag, C-terminus, HEK293) (NAC-REC31807-100, NativeAntigen, ordered via Biozol, Germany); SARS-CoV-2 spike proteins $\mathrm{S}_{1}$ subunit, purity $>90 \%$, MW = 78.3 kDa, Tag-free, human cell, (GenScript, USA); lyophilized human PF4 isolated from platelets (Chromatec, Greifswald, Germany); UFH Heparin-Natrium-25000 (Ratiopharm, Ulm, Germany); fresh platelets purified from the whole blood of healthy volunteers; anti-CD42a Alexa 647-PE and anti-CD62a-FITC antibodies (Biolegend, San Diego, USA); TRAP (Hart Biologicals, USA).

\section{Quartz crystal microbalance (QCM)}

All preparations and experiments were done at room temperature (RT). The quartz sensor QSX 301 with a resonance frequency of $4.95 \mathrm{MHz} \pm 50 \mathrm{kHz}$ (Biolin Scientific Darmstadt, Germany) was cleaned in a 5:1:1 mix of $\mathrm{H}_{2} \mathrm{O}: \mathrm{NH}_{3}: \mathrm{H}_{2} \mathrm{O}_{2}$ solution in an ultrasonic bath for 10 min. ${ }^{38}$ After rinsing with water and ethanol and drying with nitrogen, a self-assembled monolayer (SAM) of cysteamine and glutaraldehyde which contains functional aldehyde (-CHO) groups for binding of protein, was formed on the sensors. PF4 of $20 \mu \mathrm{g} / \mathrm{ml}$ was covalently immobilized on the SAM layer for 15 min before blocking free aldehyde (-CHO) groups with $1 \mathrm{M}$ ethanolamine for 1 hour. After rinsing with PBS, $2.5 \mu \mathrm{g} / \mathrm{ml} \mathrm{SP}$ was added for binding with PF4 on the chip at a pumping speed of $100 \mu \mathrm{L} / \mathrm{min}$ with an incubation time of 10 minutes. The real-time resonant frequency change was recorded at the third overtone due to stability constraints at a higher order. QCM real-time resonant frequency changes were observed on Qsoft software (version

2.5.22.707, Q sense, Biolin Scientific, Europe) and analyzed using the Sauerbrey equation ${ }^{39}$ through Qtools software (version 3, Quantum Design, Darmstadt, Germany). 


\section{Dynamic light scattering (DLS)}

DLS experiments were performed using our previous protocol testing with HIT antibodies. ${ }^{15}$, ${ }^{40,41}$ To test if SP cluster PF4, SP up to $40 \mu \mathrm{g} / \mathrm{ml}$ was titrated in a cuvette containing PF4 of $20 \mu \mathrm{g} / \mathrm{ml}$ in water. The changes in the hydrodynamic diameter of proteins were measured in water at $20^{\circ} \mathrm{C}$ and light scattering was detected at $173^{\circ}$ using 15 repetitions using the Zetasizer Nano-S system (Malvern Instruments Ltd., Malvern, UK). The change in the surface zeta potential of PF4 was determined by titrating SP concentration up to $10 \mu \mathrm{g} / \mathrm{ml}$ in a folded capillary zeta cell containing PF4 of $20 \mu \mathrm{g} / \mathrm{mL}$ in water ( $\mathrm{pH} 7.4$, conductivity of 0.318 $\mathrm{mS} / \mathrm{cm})$. The migration speed in an electric field was assessed with DLS for 10 repetitions. Data analysis was performed using the Zetasizer software, version 7.11 (Malvern Instruments Ltd., Malvern, UK) and Origin software, version 7.5.

\section{Single-molecule force spectroscopy (SMFS)}

We applied our standard protocol to functionalize cantilevers and solid surfaces. ${ }^{15,40,42}$ Briefly, both cantilevers with spring constants of $30 \mathrm{pN}$ and $6 \mathrm{pN}$ (Biolevers, Olympus, Japan) and glass substrates were first cleaned and coated with $1 \mathrm{mg} / \mathrm{mL}$ alpha-thio-omega-carboxy poly(ethylene glycol) (HS-PEG-COOH, PEG, MW= 3400 Da, Iris Biotech GmbH, Marktredwitz, Germany) before the activation of $-\mathrm{COOH}$ groups for $1 \mathrm{~h}$ in an amine coupling kit solution (EDC:NHS, 1:1 volume, Biocore, Uppsala, Sweden). Subsequently, the cantilevers were incubated at RT for $1 \mathrm{~h}$ in SP of $70 \mu \mathrm{g} / \mathrm{ml}$ (Biozol, Munich, Germany). The solid surfaces were incubated overnight at $4^{\circ} \mathrm{C}$ with PF4 $(20 \mu \mathrm{g} / \mathrm{ml})$ or PF4/H complexes formed by $20 \mu \mathrm{g} / \mathrm{mL}$ PF4 and 0.5 U/ml UFH (Iduron Ltd., Manchester, UK). SMFS measurements were carried out in PBS with the JPK NanoWizard 3 (Berlin, Germany) with 900 force curves for each condition. The binding forces were collected using the JPK data processing software (version 
4.4.18+). The mean rupture force values and their corresponding errors were determined by applying Gaussian fits to the data using Origin software (version 8.6).

\section{Enzyme-linked immunosorbent assay (ELISA)}

PF4/SP ELISA was performed by coating PF4 of $20 \mu \mathrm{g} / \mathrm{ml}$ in DPBS overnight at $4^{\circ} \mathrm{C}$ on a 96well plate and then blocked with $7.5 \%$ goat serum as described for HIT ELISA. ${ }^{43}$ After rinsing five times with DPBS, $100 \mu \mathrm{l} \mathrm{SP}$ of $10 \mu \mathrm{g} / \mathrm{ml}$ was incubated on PF4 coated plates for $1 \mathrm{~h}$ at RT for binding. After removal of unbound SP, anti-SP antibody conjugate (Biozol, Germany), 1:500 dilution in DPBS was added for $1 \mathrm{~h}$ at RT. Wells were washed with DPBS and $100 \mu \mathrm{l}$ anti-mouse IgG HRP (1:50000 dilution) were incubated for $1 \mathrm{~h}$ at RT. Wells were washed five times with DPBS and 100 TMB solution was added for 5 min before stopping the reaction by $100 \mu \mathrm{H} \mathrm{H}_{2} \mathrm{SO}_{4}$. Plate was ready to be measured at $450 \mathrm{~nm}$ absorbance for optical density (OD).

\section{Isolation of human platelets}

Human blood from healthy donors who were drug-free within the previous 10 days was collected into a tube of ACD-A 1.5 mL BD-Vacutainer (Fresenius Kabi, Bad Homburg, Germany) as previously described. ${ }^{44-45}$ Platelet-rich plasma (PRP) was first obtained by centrifugation at $120 \mathrm{~g}$ for $20 \mathrm{~min}$ at room temperature. To isolate platelets, PRP in the presence of $15 \%$ acidcitrate dextrose (ACD-A, Fresenius Kabi, Germany) and 2.5 U/ml Apyrase (grade IV SIGMA, Munich, Germany) was centrifuged at $650 \mathrm{~g}$ for $7 \mathrm{~min}$. The platelet pellet was resuspended in buffer pH 6.3 composed of $137 \mathrm{mM} \mathrm{NaCl}, 2.7 \mathrm{mM} \mathrm{KCl}, 11.9 \mathrm{mM} \mathrm{NaHCO}_{3}, 0.4 \mathrm{mM} \mathrm{Na}_{2} \mathrm{HPO}_{4}$, 2.5 U/ml Hirudin, and incubated for $15 \mathrm{~min}$ at $37^{\circ} \mathrm{C}$ before centrifuging at $650 \mathrm{~g}$ for $7 \mathrm{~min}$. 
Platelet pellets were again carefully resuspended in suspension buffer and adjusted to a concentration of $300 \times 10^{9} / \mathrm{L}$ using a blood counter (pocH-100i, SYSMEX, Germany) and then incubated for $45 \mathrm{~min}$ at $37^{\circ} \mathrm{C}$ before use.

\section{Confocal laser scanning microscopy (CLSM) imaging of platelet morphology}

The heparin-induced platelet aggregation (HIPA) tests were performed as previously described for HIT antibodies. ${ }^{15}$ Briefly, $75 \mu \mathrm{L}$ of washed platelets $(300,000$ platelets/ $\mu \mathrm{l})$ was incubated with $20 \mu \mathrm{L}$ SP of 10 and $50 \mu \mathrm{g} / \mathrm{ml}$ concentrations (final) either without, with low $(0.2 \mathrm{U} / \mathrm{ml})$ or high $(100 \mathrm{U} / \mathrm{ml})$ unfractionated heparin concentration. Samples were added to microtiter plates and incubated on a magnetic stirrer (1000 rpm) for 45 minutes at RT.

For imaging with CLSM, samples were transferred to Petri dishes and kept at RT for 15 min before adding 4\% PFA for fixation for $20 \mathrm{~min}$ at RT. ${ }^{45}$ Anti-CD42a Alexa 647 antibodies (1:1000 dilution) were added to the immobilized platelets and incubated overnight at $4^{\circ} \mathrm{C}$. Unbound antibodies were removed by rinsing with PBS before imaging by the CLSM (LSM710, Carl Zeiss, Gottingen, Germany) at RT in the dark. ImageJ and Origin (version 8.6) software were used to further process the images and to quantify the fluorescence intensity detected on each sample.

To minimize $\mathrm{PF} 4$ release, platelet aggregation tests were incubated at $37^{\circ} \mathrm{C}$ for $1 \mathrm{~h}$ in static condition without stirring in the presence of SP concentration up to $50 \mu \mathrm{g} / \mathrm{ml}$. The PF4:SP concentration ratio that induces platelet aggregation was determined by titrating PF4 up to $30 \mu \mathrm{g} / \mathrm{ml}$ into a platelet sample (300,000 platelets/ $\mu \mathrm{l})$ containing $10 \mu \mathrm{g} / \mathrm{ml} \mathrm{SP}$.

\section{Flow cytometry}


Platelets $(300,0000 / \mu 1)$ in suspension buffer were incubated with either SP or a mixture of SP with PF4 of different concentrations or 100 $\mu \mathrm{M}$ TRAP (Hart Biologicals, USA) as a positive control for $1 \mathrm{~h}$ at $37^{\circ} \mathrm{C}$. To detect platelets, samples were incubated with anti-CD42a-PE antibody (1:1000 dilution) for $1 \mathrm{~h}$ at $37^{\circ} \mathrm{C}$. To detect $\mathrm{P}$-selectin expression due to activation of platelets, samples were incubated with CD62P- FITC antibody (1:1000 dilution) for $1 \mathrm{~h}$ at $37^{\circ} \mathrm{C}$. After washing at $2200 \mathrm{rpm}$ centrifugation for $7 \mathrm{~min}$, the samples were diluted in $500 \mu \mathrm{l}$ FACS buffer and excited by the blue laser at $488 \mathrm{~nm}$. Fluorescence emission of PE and FITC fluorophores were correspondingly detected at 585/40 nm and 533/30 nm filters by CytoFLEX LX (Beckman Coulter). Fluorescence compensation was applied to correct emission spectra overlap between FITC and PE fluorophores using single-color-labeled preparations. Fifty thousand events in the CD42+ gate were acquired for each sample. Different features were recorded for each event such as size and fluorescence intensity in channels and analyzed by CytExpert.

\section{Results}

\section{SARS-CoV-2-SP clusters PF4}

As SARS-CoV-2 spike protein ${ }^{46}$ composes of $S_{1}$ and $S_{2}$ subunits (Fig. 1A, top), we first compared characteristics of these two subunits by tracking their hydrodynamic sizes and surface zeta potential (Fig. 1A, bottom). The $\mathrm{S}_{2}$ subunit (red box) has a zeta potential around zero and hydrodynamic size of $\sim 250 \mathrm{~nm}$ while these are about $-5 \mathrm{mV}$ for the $\mathrm{S}_{1}$ subunit, indicating a high tendency of forming an aggregation of $S_{2}$ subunits. The $S_{1}$ subunit shows a negative zeta potential of $\sim 5 \mathrm{mV}$ and the hydrodynamic size of $\sim 50 \mathrm{~nm}$, indicating a low tendency of aggregation of these proteins. We have previously shown that most HIT 
antibodies which have surface potential around zero are active and induce platelet aggregation. ${ }^{40}$ Thus, the $\mathrm{S}_{2}$, which is simplified by SP, was selected for further investigation.

We then mixed SP with PF4 and identified variation in hydrodynamic size and zeta potential of the mixture using Dynamic light scattering (DLS) (Fig. B). The theoretical size of $\mathrm{S} 2$ subunit $(\mathrm{MW}=115 \mathrm{kDa},<10 \mathrm{~nm})$ and PF4 tetramer $(\mathrm{MW}=32 \mathrm{kDa},<5 \mathrm{~nm})$ are smaller than the experimental ones (Fig. 1C). This is because hydrodynamic size does not reflect the real size of proteins. The low ionic concentration medium produced an extended double layer of ions ${ }^{47}$ around the molecules, which reduced the diffusion speed resulting in a larger hydrodynamic diameter. Furthermore, owing to the highly hydrophobic characteristics of PF4 molecules, they tend to come closer to each other in many buffers as previously described. ${ }^{41}$ When titrating SP into a cuvette containing PF4 $(20 \mu \mathrm{g} / \mathrm{ml})$, an increase in the size of the PF4/SP complex up to $2.5 \mu \mathrm{g} / \mathrm{ml} \mathrm{SP}$ was observed, and at $40 \mu \mathrm{g} / \mathrm{ml}$ SP the size of particles was significantly reduced. This indicates that the maximal size of PF4/SP complexes was formed at PF4:SP molar ratio of $28.8(20 \mu \mathrm{g} / \mathrm{ml}$ PF4: $2.5 \mu \mathrm{g} / \mathrm{ml} \mathrm{SP})$. The binding of SP with PF4 was also observed by changes in surface zeta potential (Fig. 1D). The SP has a surface zeta potential $\sim$ zero while PF4 has a ring of positively charged lysine ${ }^{48}$ that exhibits a zeta potential around $+6 \mathrm{mV}$. When adding SP of various concentrations to PF4 (20 $\mu \mathrm{g} / \mathrm{ml})$, the zeta potential of the mixture switched to negative values. This indicated that the PF4/SP complexes are not formed by a simple electrostatic interaction like in the case of the interaction between PF4 and heparin, in which heparin neutralizes the positive charges of PF4. ${ }^{49}$ We have previously shown that heparin brought two hydrophobic PF4 molecules together due to the neutralization of surface charges on PF4 by heparin, causing a merge of multiple hydrophobic PF4 molecules and changed the conformation of PF4. ${ }^{50}$ As SP protein exhibits a mixture of complex surfaces with different properties,${ }^{31}$ it is plausible that PF4 first binds to the SP region of negatively charged residues and then undergoes conformational 
changes by interacting with the hydrophobic or hydrophilic residues of SP that switched the surface zeta potential of PF4 from positive to negative values. Thus, the SP might also bring PF4 closely to each other which causes a merge of multiple PF4 molecules in a similar way heparin does, resulting in large conformational changes in PF4s. When heparin was added, the size of the complexes was strongly reduced, indicating the ability of heparin in inhibition of the binding between PF4 and SP. These binding features of SARS-CoV-2-SP are somewhat similar to those of HIT autoantibodies with PF4 molecules. ${ }^{27}$

We further utilized quartz crystal microbalance (QCM), which is a label-free and highly sensitive technique, to detect binding of SP $\left(\mathrm{S}_{2}\right)$ with PF4 based on additional mass or frequency changes on a real-time basis (Fig. 1E). QCM spectra showed a strong frequency shift (Fig. 1F) or high mass change (Fig. 1G) when SP of $2.5 \mu \mathrm{g} / \mathrm{ml}$ was added to PF4 coated sensor. These results suggested that there was a binding reaction between SP and PF4.

\section{Binding force between SARS-CoV-2 SP and PF4}

We next determined the binding force of interactions between PF4 and SP using singlemolecule force spectroscopy (SMFS) based atomic force microscopy. A single SARS-CoV2-SP was immobilized on a cantilever while PF4 molecules were coated onto a glass substrate (Fig. 2A). As PF4 can form complexes with heparin (H) that causes a conformational change in PF4, resulting in binding epitopes for HIT antibodies that activate platelets. Similarly, PF4s form complexes with polyanions on the platelet membrane, inducing PF4/polyanion complexes with identical characteristics as PF4/H complexes. Here, we additionally immobilized PF4/H on the substrate and tested binding with SP. The SP interacted with PF4 or PF4/H complexes when the cantilevers approach the substrate, and their binding forces were measured when the tip ruptured from the substrate (Fig. 2A). The magnitude of the binding force of SP with PF4 is similar to that with PF4/H (Fig. 2B, C). 
Even though PF4/H complexes are larger and may offer more binding sites than PF4 alone, the contact area of the immobilized SP to these molecules may not significantly different, and therefore, did not induce a strong increase in force. However, PF4 slightly showed higher variation in both force $(32.4 \pm 7.4 \mathrm{pN})$ and frequency of interaction $(274.7 \pm 189.1$ counts $)$ than PF4/H complexes (32.9 $\pm 5.5 \mathrm{pN}$ and $247.8 \pm 136.2$ counts) (Fig. 2C, D). Additionally, at $>50 \mathrm{pN}$, SP showed higher interaction when interacting with PF4/H complexes than with PF4 alone. This difference is caused by an optimal exposure of binding epitope in PF4/H complexes while various forms of PF4 including monomer, dimer, trimer, and tetramer lead to the large variation of binding force with SP. Consistent with the above results obtained by biophysical methods, SP also showed a strong binding when interacting with PF4 immobilized on a 96-well plate as tested in ELISA (Fig. 2E).

\section{PF4/SARS-CoV-2 SP complexes induced platelet aggregation}

As the SARS-CoV-2-SP and HIT autoantibodies ${ }^{27}$ have a similar characteristic in clustering PF4 molecules while the complexes of PF4 and HIT autoantibodies activate platelets, we next tested if PF4/SP complexes also induce platelet aggregation in functional HIT assay platforms. We have previously used heparin-induced platelet aggregation (HIPA) to identify if antibodies in patients suspected of HIT activate platelets. If the HIPA test result is positive in the presence of low heparin concentration $(0.2 \mathrm{U} / \mathrm{ml})$, the patient has typical HIT, and if it is positive in the absence of heparin, the patient suffers from autoimmune HIT ${ }^{27}$ Heparin at high concentration $(100 \mathrm{U} / \mathrm{ml})$ is known to inhibit platelet aggregation. Here, HIT antibodies were replaced with SP in HIPA tests. At the end of HIPA experiments, samples were immobilized on glass substrates and stained for imaging with confocal laser scanning microscopy (CLSM) (Fig. 3). Without heparin, platelets did not aggregate in the absence of SP (Fig. 3A), but aggregate at $10 \mu \mathrm{g} / \mathrm{ml} \mathrm{SP} \mathrm{(Fig.} \mathrm{3B)} \mathrm{and} \mathrm{were} \mathrm{much} \mathrm{stronger} \mathrm{at} 50 \mu \mathrm{g} / \mathrm{ml} \mathrm{SP}$ 
(Fig. 3C). This is a feature of HIT autoantibodies. Low $(0.2 \mathrm{U} / \mathrm{ml})$ heparin concentration reduced platelet aggregation (Fig. 3D, E) while high heparin concentration (100 U/ml) completely inhibited platelets aggregation (Fig. 3F, G) at both $10 \mu \mathrm{g} / \mathrm{ml}$ and $50 \mu \mathrm{g} / \mathrm{ml} \mathrm{SP}$. Quantification of all particle sizes (Fig. 3H) or particles with size $>20 \mu \mathrm{m}^{2}$ (Fig. 3I) showed the largest size and highest frequency (\%) of formation of large particles at $50 \mu \mathrm{g} / \mathrm{ml} \mathrm{SP}$.

In HIPA experiments, PF4 molecules were released from platelet $\alpha$-granules while stirring the platelet samples. Thus, the results reflect that upon binding, the resulting PF4/SP complexes induced platelet aggregation. To clarify if SP induces platelet aggregation only in the presence of PF4, we next minimized PF4 release by incubating washed platelets with SP at static conditions and quantified the size of platelets (Supplementary Fig. 1). Some platelets with a larger size than their native size were observed at $10 \mu \mathrm{g} / \mathrm{ml} \mathrm{SP}$ whereas higher SP concentration reduced platelet extent (Fig. 4A). Quantification of particle sizes showed the highest frequency of particles $>9 \mu \mathrm{m}^{2}$ at $10 \mu \mathrm{g} / \mathrm{ml}$, but it reduced gradually as SP concentration increases (Fig. 4B). In this condition, the unknown concentration of PF4 released from washed platelets did not allow us to determine the relationship between PF4:SP concentration and platelet morphology. To further understand if PF4 together with SP at a defined concentration affects platelets, we titrated PF4 up to $30 \mu \mathrm{g} / \mathrm{ml}$ into washed platelets in the presence of $10 \mu \mathrm{g} / \mathrm{ml} \mathrm{SP}$. We observed that the frequency of platelets (\%) at size $>5 \mu \mathrm{m}^{2}$ significantly increased at PF4 concentration between 10 and $20 \mu \mathrm{g} / \mathrm{ml}$ (Fig. 4C). In these experiments, we observed a clear effect of SP on platelet's state and PF4 played an important role in inducing platelet aggregation, especially at a certain PF4:SP molar concentration ratio (between 3.6 and 7.2). We further used a P-lectin maker (CD62P) to track if SP induces platelet activation by flow cytometry (Supplementary Fig. 2). SP without PF4 induced an increase of platelet activation at higher concentrations and further enhanced activation in the presence of PF4 but also followed a concentration-dependent manner. This 
indicates a synergy effect between SP and PF4 in activating platelets. It is, therefore, necessary to detect not only PF4-antibodies but also PF4:SP concentration ratio to identify a better treatment strategy for patients suspected of thrombosis thrombocytopenia.

\section{Discussion}

By utilizing multiple analytical techniques, we found that SARS-CoV-2 SP clusters PF4. It induced conformational changes in PF4 and switched the surface zeta potential of PF4 from positive to negative values. The formed PF4/SP complexes induced platelet aggregation in a concentration-dependent manner.

From our observation, we propose a mechanism for SARS-CoV-2-induced thrombocytopenia in Covid-19 patients (Fig. 5). The binding of the SARS-CoV-2 virus to positively charged PF4 molecules forms antigenic PF4/virus complexes (Fig. 5A). In the HIT system, HIT antibodies are produced due to immune response to the ultra-large antigenic PF4/Heparin complexes which can be up to several micrometers in size. ${ }^{51,41}$ As the SARSCoV-2 with a size of $60-140 \mathrm{~nm},{ }^{27}$ the cross-linking among PF4 molecules and viruses can develop large enough immune complexes that on one hand mediate/activate platelets (Fig. 5B) and on the other hand promote B-cells to producing PF4-antibodies in a similar way ultra-large antigenic PF4/H complexes do (Fig. 5C). Consistently, recent reports showed that platelet-activating PF4-antibodies are detected in Covid-19 infected patients..$^{9,22}$

Previously, we reported that only a low concentration of PF4-antibodies or HIT autoantibodies $(\sim 5 \mu \mathrm{g} / \mathrm{ml})$ induced massive platelet activation even in the absence of heparin. ${ }^{27}$ These antibodies activate human platelets, monocytes, and neutrophils. They also bind to endothelial cells through PF4/polyanion complexes, ${ }^{14,35}$ inducing a frequent immune-mediated adverse drug reaction in form of the life-threatening autoimmune HIT. ${ }^{52}$ The synergic connection between the PF4/Virus in Covid-19 patients and PF4-antibodies can cause unusual 
thrombotic thrombocytopenia (Fig. 5D). This can be the mechanism for excessive procoagulant activity observed in Covid-19 patients. However, the degree of complication may occur differently depending on the amount of PF4 and SP in individuals with unique biological backgrounds.

In addition, we suggest that the interaction of SP and PF4 offers a possible underlying mechanism for a high rate of clotting effects in vaccinated patients. The Ad26.COV2.S and ChAdOx1 nCoV-19 (AstraZeneca and Johnson Johnson) Covid-19 vaccines caused higher clotting events than BNT162b2 and mRNA-1273 vaccines (Pfizer, Moderna). ${ }^{19}$ The BNT162b2 and mRNA-1273 Covid-19 encapsulated mRNA (called mRNA-based vaccine) in lipid nanoparticles that encode the virus spike protein antigen whereas the Ad26.COV2. S and $\mathrm{ChAdOx} 1 \mathrm{nCoV}-19$ vaccines use recombinant more tolerated chimpanzee adenoviral vectors encoding the spike protein of the virus (called vector-based vaccines). ${ }^{53}$ These two latter vaccines require an additional step to produce mRNA from DNA. ${ }^{54}$ In this process, transcription of wildtype and codon-optimized spike open reading frames enables alternative splice events that lead to C-terminal truncated, soluble/partial spike proteins that do not contain a necessary part for adhering to cells as they should. Therefore, these soluble spike proteins can not trigger immune cells to produce anti-SP antibodies but they can enter the blood circulation, forming complexes with PF4 that trigger the formation of PF4-antibodies (Fig. 6). When testing VITT patients sera in HIPA, Greinacher et al found that these sera increased platelet activation overtime counted from the first day of being vaccinated with AstraZeneca vaccine. ${ }^{21}$ These results suggest that the concentration of the soluble SP increase overtime. However, the authors also found that VITT occurs only from day 5 after vaccination which is consistent with our finding that the platelet activation occurs only when a critical PF4:SP concentration ratio reaches. In addition to soluble SPs, cell fragments carrying SPs that are developed by cell disrupting/dying during the immune response to 
vaccines. These SP carriers can also cluster PF4, forming antigenic PF4/SP-cell-fragment complexes that also adhere and activate platelets as well as trigger the development of PF4antibodies.

Furthermore, the adenoviruses have an isoelectric point at $\sim \mathrm{pH} 6.2,{ }^{55-56}$ meaning that they have a neutrally charged surface at this $\mathrm{pH}$. However, by entering blood circulation $(\mathrm{pH}$ between 7.35 and 7.45), the neutral surfaces of adenoviruses can be switched to negative net charges. We speculate that in some vaccinated individuals with rare biological characteristics, a high amount of PF4 is secreted before and further enhanced after vaccination. High density together with positively charged residues of PF4 can facilitate binding with the negative net charges of adenovirus vaccine, forming antigenic PF4/vaccine complexes. Consistently, the binding of PF4 to the Astrazeneca vaccine has been observed in vitro. ${ }^{57}$ If this vaccine enters the blood circulation, the formed PF4/vaccine can also trigger the production of PF4antibodies.

Together, these factors strongly and quickly induce VITT. As different factors including PF4/SP, PF4/vaccine complexes, and PF4/SP-cell-fragment can trigger the production of PF4-antibodies after vaccination, a high concentration of these antibodies will be developed. Consistently, it has been shown that high OD $\sim 3$ was obtained in PF4/Heparin ELISA when tested with VITT patients sera ${ }^{21}$ while HIT sera show OD 2 units ${ }^{58}$.

The soluble SPs are an add-in complication to the basic side effect induced by mRNA-based vaccines. The mRNA-based vaccine works simply by entering the cell and produces SP that diffuses and adheres on cells membrane following by the production of antispike protein antibodies (Fig. 6). This explains the higher frequency of thrombotic thrombocytopenia after vaccination with vector-based vaccine as compared with mRNAbased vaccines. The frequency of side effects, however, depends on the efficiency of the 
vaccines in producing spike proteins as we observed a reduction of platelet aggregation at too high or too low SP concentration.

Although the formation of PF4/SP complexes induces platelet aggregation, the outcome of the Covid-19 patients differs from vaccinated individuals. In Covid-patients, the uncontrollable amount of SP on viruses mainly dominates in the lung, and therefore, the formation of blood clots in this organ blocks the airway that induces severe acute respiratory syndrome leading to death. In vaccinated individuals, the blood clots are mainly formed at the site of injection and are rarely found in other organs. Thus, severe side effects in vaccinated individuals are rare depending on the location of the blood clots. This also explains why the severely ill rate in vaccinated individuals is much lower than in Covid-19 patients.

As PF4/SP complexes also induce platelet aggregation, we suggest an additional consideration to the guidance from the $\mathrm{GTH}^{59}$ and $\mathrm{ISTH}^{60}$ for diagnostic and therapeutic algorithm in patients with the vaccine (AstraZeneca)-induced thrombocytopenia (VITT). If serum is negative in the screening test for HIT antibodies but positive in HIPA/SRA, the critical PF4:SP concentration ratio that forms platelet-activating PF4/SP complexes is reached. In this case, heparin or even high-dose heparin treatment is possible (Fig. 7).

\section{Acknowledgments}

This work was supported by the Freistaat Thüringen (Thüringer Ministerium für Wirtschaft, Wissenschaft und Digitale Gesellschaft, TMWWDG, Germany) and the Deutsche Forschungsgemeinschaft (DFG, Germany, Project number: NG 133/1-2). We thank Prof. Andreas Greinacher for his constant support and throughtful discussion; the Nieren- und Dialysezentrum Eichsfeld for helping us with platelet donation. 


\section{Author contributions}

THN conceived the project, designed experiments, analyzed the data, and wrote the manuscript. LYC performed SMFS, platelet aggregation, and CLSM experiments and analyzed the data. NZK performed QCM experiments and analyzed the data. AL performed DLS experiments. VCB designed experiments, discussed the data, and wrote the manuscript. PFZ and DH wrote the manuscript. All authors agreed with the final version of the manuscript.

\section{Competing interests}

The authors declare no competing financial interests. 


\section{References}

1. Zhu, N.; Zhang, D.; Wang, W.; Li, X.; Yang, B.; Song, J.; Zhao, X.; Huang, B.; Shi, W.; Lu, R.; Niu, P.; Zhan, F.; Ma, X.; Wang, D.; Xu, W.; Wu, G.; Gao, G. F.; Tan, W.; China Novel Coronavirus, I.; Research, T., A Novel Coronavirus from Patients with Pneumonia in China, 2019. N Engl J Med 2020, 382 (8), 727-733.

2. WHO, WHO Coronavirus Disease (COVID-19) Dashboard. https://covid19.who.int 04 June, 2021.

3. Hanif, A.; Khan, S.; Mantri, N.; Hanif, S.; Saleh, M.; Alla, Y.; Chinta, S.; Shrestha, N.; Ji, W.; Attwood, K.; Adrish, M.; Jain, K. R., Thrombotic complications and anticoagulation in COVID-19 pneumonia: a New York City hospital experience. Ann Hematol 2020, 99 (10), 2323-2328.

4. Tang, N.; Li, D.; Wang, X.; Sun, Z., Abnormal coagulation parameters are associated with poor prognosis in patients with novel coronavirus pneumonia. J Thromb Haemost 2020, 18 (4), 844-847.

5. Cui, S.; Chen, S.; Li, X.; Liu, S.; Wang, F., Prevalence of venous thromboembolism in patients with severe novel coronavirus pneumonia. J Thromb Haemost 2020, 18 (6), 14211424.

6. Yang, X.; Yang, Q.; Wang, Y.; Wu, Y.; Xu, J.; Yu, Y.; Shang, Y., Thrombocytopenia and its association with mortality in patients with COVID-19. J Thromb Haemost 2020, 18 (6), 1469-1472.

7. Cattaneo, M.; Bertinato, E. M.; Birocchi, S.; Brizio, C.; Malavolta, D.; Manzoni, M.; Muscarella, G.; Orlandi, M., Pulmonary Embolism or Pulmonary Thrombosis in COVID-19? Is the Recommendation to Use High-Dose Heparin for Thromboprophylaxis Justified? Thromb Haemost 2020, 120 (8), 1230-1232.

8. Tang, N.; Bai, H.; Chen, X.; Gong, J.; Li, D.; Sun, Z., Anticoagulant treatment is associated with decreased mortality in severe coronavirus disease 2019 patients with coagulopathy. $J$ Thromb Haemost 2020.

9. Dragonetti, D.; Guarini, G.; Pizzuti, M., Detection of anti-heparin-PF4 complex antibodies in COVID-19 patients on heparin therapy. Blood Transfus 2020, 18 (4), 328.

10. Nazy, I.; Jevtic, S. D.; Moore, J. C.; Huynh, A.; Smith, J. W.; Kelton, J. G.; Arnold, D. M., Platelet-activating immune complexes identified in critically ill COVID-19 patients suspected of heparin-induced thrombocytopenia. J Thromb Haemost 2021.

11. Phan, X. T.; Nguyen, T. H.; Tran, T. T.; Huynh, T. T.; Hoang, T. T.; Nguyen, V. V.; Pham, T. N. T., Suspected heparin-induced thrombocytopenia in a COVID-19 patient on extracorporeal membrane oxygenation support: a case report. Thromb J 2020, 18 (1), 37.

12. Althaus, K.; Marini, I.; Zlamal, J.; Pelzl, L.; Singh, A.; Haberle, H.; Mehrlander, M.; Hammer, S.; Schulze, H.; Bitzer, M.; Malek, N.; Rath, D.; Bosmuller, H.; Nieswandt, B.; Gawaz, M.; Bakchoul, T.; Rosenberger, P., Antibody-induced procoagulant platelets in severe COVID-19 infection. Blood 2021, 137 (8), 1061-1071.

13. Greinacher, A., Heparin-Induced Thrombocytopenia. N Engl J Med 2015, 373 (19), 1883-4. 
14. Warkentin, T. E.; Chong, B. H.; Greinacher, A., Heparin-induced thrombocytopenia: towards consensus. Thromb Haemost 1998, 79 (1), 1-7.

15. Nguyen, T. H.; Medvedev, N.; Delcea, M.; Greinacher, A., Anti-platelet factor 4/polyanion antibodies mediate a new mechanism of autoimmunity. Nat Commun 2017, 8, 14945.

16. Preti, P. S.; Russo, M.; Caneva, L.; Reduzzi, M.; Calabretta, F.; Spataro, C.; Grimaldi, P.; De Amici, M.; Testa, G.; Iotti, G. A.; Mojoli, F.; Di Sabatino, A., Increased prevalence of heparin induced thrombocytopenia in COVID-19 patients. Thromb Res 2021, 203, 33-35.

17. Belete, T. M., A review on Promising vaccine development progress for COVID-19 disease. Vacunas 2020, 21 (2), 121-128.

18. Bennet, B. M.; Wolf, J.; Laureano, R.; Sellers, R. S., Review of Current Vaccine Development Strategies to Prevent Coronavirus Disease 2019 (COVID-19). Toxicol Pathol 2020, 48 (7), 800-809.

19. Aleem, A.; Nadeem, A. J., Coronavirus (COVID-19) Vaccine-Induced Immune Thrombotic Thrombocytopenia (VITT). In StatPearls, Treasure Island (FL), 2021.

20. Scully, M.; Singh, D.; Lown, R.; Poles, A.; Solomon, T.; Levi, M.; Goldblatt, D.; Kotoucek, P.; Thomas, W.; Lester, W., Pathologic Antibodies to Platelet Factor 4 after ChAdOx1 nCoV-19 Vaccination. N Engl J Med 2021.

21. Greinacher, A.; Thiele, T.; Warkentin, T. E.; Weisser, K.; Kyrle, P. A.; Eichinger, S., Thrombotic Thrombocytopenia after ChAdOx1 nCov-19 Vaccination. N Engl J Med 2021.

22. Althaus, K.; Moller, P.; Uzun, G.; Singh, A.; Beck, A.; Bettag, M.; Bosmuller, H.; Guthoff, M.; Dorn, F.; Petzold, G. C.; Henkes, H.; Heyne, N.; Jumaa, H.; Kreiser, K.; Limpach, C.; Luz, B.; Maschke, M.; Muller, J. A.; Munch, J.; Nagel, S.; Potzsch, B.; Muller, J.; Schlegel, C.; Viardot, A.; Bazner, H.; Wolf, M.; Pelzl, L.; Warm, V.; Willinek, W. A.; Steiner, J.; Schneiderhan-Marra, N.; Vollherbst, D.; Sachs, U. J.; Fend, F.; Bakchoul, T., Antibodymediated procoagulant platelets in SARS-CoV-2- vaccination associated immune thrombotic thrombocytopenia. Haematologica 2021.

23. Schultz, N. H.; Sorvoll, I. H.; Michelsen, A. E.; Munthe, L. A.; Lund-Johansen, F.; Ahlen, M. T.; Wiedmann, M.; Aamodt, A. H.; Skattor, T. H.; Tjonnfjord, G. E.; Holme, P. A., Thrombosis and Thrombocytopenia after ChAdOx1 nCoV-19 Vaccination. $N$ Engl J Med 2021, 384 (22), 2124-2130.

24. P, G. D. a. M., Doctor's Death After Covid Vaccine Is Being Investigated. The New York Times Jan. 12, 2021.

25. Lee, E. J.; Cines, D. B.; Gernsheimer, T.; Kessler, C.; Michel, M.; Tarantino, M. D.; Semple, J. W.; Arnold, D. M.; Godeau, B.; Lambert, M. P.; Bussel, J. B., Thrombocytopenia following Pfizer and Moderna SARS-CoV-2 vaccination. American journal of hematology 2021, 96 (5), 534-537.

26. Meredith, S., Germany, France, Spain and Italy become latest countries to suspend AstraZeneca vaccine over blood clot fears. CNBC Marh 15, 2021.

27. Bar-On, Y. M.; Flamholz, A.; Phillips, R.; Milo, R., SARS-CoV-2 (COVID-19) by the numbers. Elife 2020, 9.

28. Song, W.; Gui, M.; Wang, X.; Xiang, Y., Cryo-EM structure of the SARS coronavirus spike glycoprotein in complex with its host cell receptor ACE2. PLoS Pathog 2018, 14 (8), e1007236. 
29. Lan, J.; Ge, J.; Yu, J.; Shan, S.; Zhou, H.; Fan, S.; Zhang, Q.; Shi, X.; Wang, Q.; Zhang, L.; Wang, X., Structure of the SARS-CoV-2 spike receptor-binding domain bound to the ACE2 receptor. Nature 2020, 581 (7807), 215-220.

30. Belouzard, S.; Millet, J. K.; Licitra, B. N.; Whittaker, G. R., Mechanisms of coronavirus cell entry mediated by the viral spike protein. Viruses 2012, 4 (6), 1011-33.

31. PH, P., Charged amino acids may promote coronavirus SARS-CoV-2 fusion with the host cell. AIMS Biophysics 2021, 8 (1).

32. Kowalska, M. A.; Rauova, L.; Poncz, M., Role of the platelet chemokine platelet factor 4 (PF4) in hemostasis and thrombosis. Thromb Res 2010, 125 (4), 292-6.

33. Zaid, Y.; Puhm, F.; Allaeys, I.; Naya, A.; Oudghiri, M.; Khalki, L.; Limami, Y.; Zaid, N.; Sadki, K.; Ben El Haj, R.; Mahir, W.; Belayachi, L.; Belefquih, B.; Benouda, A.; Cheikh, A.; Langlois, M. A.; Cherrah, Y.; Flamand, L.; Guessous, F.; Boilard, E., Platelets Can Associate with SARS-Cov-2 RNA and Are Hyperactivated in COVID-19. Circ Res 2020.

34. Nguyen, T. H.; Greinacher, A., Distinct Binding Characteristics of Pathogenic Anti-Platelet Factor-4/Polyanion Antibodies to Antigens Coated on Different Substrates: A Perspective on Clinical Application. ACS Nano 2018, 12 (12), 12030-12041.

35. Nguyen, T. H.; Xu, Y.; Brandt, S.; Mandelkow, M.; Raschke, R.; Strobel, U.; Delcea, M.; Zhou, W.; Liu, J.; Greinacher, A., Characterization of the interaction between platelet factor 4 and homogeneous synthetic low molecular weight heparins. J Thromb Haemost 2020, 18 (2), 390-398.

36. Sachais, B. S.; Higazi, A. A.; Cines, D. B.; Poncz, M.; Kowalska, M. A., Interactions of platelet factor 4 with the vessel wall. Semin Thromb Hemost 2004, 30 (3), 351-8.

37. Shi, G.; Morrell, C. N., Platelets as initiators and mediators of inflammation at the vessel wall. Thromb Res 2011, 127 (5), 387-90.

38. Li, X.; Wu, X.; Shi, P.; Ye, Z. G., Lead-Free Piezoelectric Diaphragm Biosensors Based on Micro-Machining Technology and Chemical Solution Deposition. Sensors (Basel) 2016, 16 (1).

39. Sauerbrey, G., Use of quartz vibration for weighing thin films on a microbalance. J. Phys. 1959, (155), 206-222.

40. Vayne, C.; Nguyen, T. H.; Rollin, J.; Charuel, N.; Poupon, A.; Pouplard, C.; Normann, N.; Gruel, Y.; Greinacher, A., Characterization of New Monoclonal PF4-Specific Antibodies as Useful Tools for Studies on Typical and Autoimmune Heparin-Induced Thrombocytopenia. Thromb Haemost 2020.

41. Bui, V. C.; Gebicka, P.; Hippe, H.; Raschke, R.; Nguyen, T. L.; Greinacher, A.; Nguyen, T. H., Physicochemical Characteristics of Platelet Factor 4 under Various Conditions are Relevant for Heparin-Induced Thrombocytopenia Testing. J Phys Chem B 2020, 124 (8), 1438-1443.

42. Nguyen, T. H.; Greinacher, A., Platelet factor 4/heparin complexes present epitopes differently on solid-phase vs platelet surfaces. Blood 2017, 129 (26), 3498-3501.

43. Juhl, D.; Eichler, P.; Lubenow, N.; Strobel, U.; Wessel, A.; Greinacher, A., Incidence and clinical significance of anti-PF4/heparin antibodies of the $\operatorname{IgG}, \operatorname{IgM}$, and IgA class in 755 consecutive patient samples referred for diagnostic testing for heparin-induced thrombocytopenia. Eur J Haematol 2006, 76 (5), 420-6. 
44. Bui CV, M. N., Apte G, Chen LY, Denker C, Greinacher A, and Nguyen TH, Response of Human Blood Platelet on Nanoscale Groove Patterns: Implications for Platelet Storage. ACS Appl. Nano Mater. 2020, 3 (7).

45. Nguyen, T. H.; Palankar, R.; Bui, V. C.; Medvedev, N.; Greinacher, A.; Delcea, M., Rupture Forces among Human Blood Platelets at different Degrees of Activation. Sci Rep 2016, 6, 25402.

46. Walls, A. C.; Park, Y. J.; Tortorici, M. A.; Wall, A.; McGuire, A. T.; Veesler, D., Structure, Function, and Antigenicity of the SARS-CoV-2 Spike Glycoprotein. Cell 2020, 181 (2), 281292 e6.

47. Leader, B.; Baca, Q. J.; Golan, D. E., Protein therapeutics: a summary and pharmacological classification. Nat Rev Drug Discov 2008, 7 (1), 21-39.

48. Cai, Z.; Yarovoi, S. V.; Zhu, Z.; Rauova, L.; Hayes, V.; Lebedeva, T.; Liu, Q.; Poncz, M.; Arepally, G.; Cines, D. B.; Greene, M. I., Atomic description of the immune complex involved in heparin-induced thrombocytopenia. Nat Commun 2015, 6, 8277.

49. Chudasama, S. L.; Espinasse, B.; Hwang, F.; Qi, R.; Joglekar, M.; Afonina, G.; Wiesner, M. R.; Welsby, I. J.; Ortel, T. L.; Arepally, G. M., Heparin modifies the immunogenicity of positively charged proteins. Blood 2010, 116 (26), 6046-53.

50. Nguyen, T. H.; Greinacher, A.; Delcea, M., Quantitative description of thermodynamic and kinetic properties of the platelet factor 4/heparin bonds. Nanoscale 2015, 7 (22), 10130-9.

51. Suvarna, S.; Espinasse, B.; Qi, R.; Lubica, R.; Poncz, M.; Cines, D. B.; Wiesner, M. R.; Arepally, G. M., Determinants of PF4/heparin immunogenicity. Blood 2007, 110 (13), 4253 60.

52. Warkentin, T. E.; Basciano, P. A.; Knopman, J.; Bernstein, R. A., Spontaneous heparininduced thrombocytopenia syndrome: 2 new cases and a proposal for defining this disorder. Blood 2014, 123 (23), 3651-4.

53. K, D. P. a. H., Blood clot fears and the Oxford-AstraZeneca vaccine: what we know. Financial Times March 152021

54. Kowarz E., K. L., Reis J., Bracharz S., Kochanek S., Marschalek R., 'Vaccine-Induced Covid-19 Mimicry" Syndrome' Splice reactions within the SARS-CoV-2 Spike open reading frame result in Spike protein variants that may cause thromboembolic events in patients immunized with vector-based vaccines. Researchsquare 2021.

55. Michen, B.; Graule, T., Isoelectric points of viruses. J Appl Microbiol 2010, 109 (2), 388-97.

56. Mouillot, L.; Netter, R., Identification of Orthopox virus by isoelectrofocusing in a granulated gel. Ann Microbiol (Paris) 1977, 128 (3), 417-9.

57. al, G. A. e., Towards Understanding ChAdOx1 nCov-19 Vaccine-induced Immune Thrombotic Thrombocytopenia (VITT). Researchsquare.

58. Nguyen, T. H.; Wesche, J.; Raschke, R.; Strobel, U.; Bui, V. C.; Delcea, M.; Greinacher, A., Reactivity of platelet-activating and nonplatelet-activating anti-PF4/heparin antibodies in enzyme immunosorbent assays under different conditions. J Thromb Haemost 2019, 17 (7), 1113-1119.

59. Oldenburg, J.; Klamroth, R.; Langer, F.; Albisetti, M.; von Auer, C.; Ay, C.; Korte, W.; Scharf, R. E.; Potzsch, B.; Greinacher, A., Diagnosis and Management of Vaccine-Related 
Thrombosis following AstraZeneca COVID-19 Vaccination: Guidance Statement from the GTH. Hamostaseologie 2021, 41 (3), 184-189.

60. ISTH, THE ISTH RELEASES INTERIM GUIDANCE ON VACCINE-INDUCED IMMUNE THROMBOTIC THROMBOCYTOPENIA (VITT). April 20, 2021 


\section{Figures and legends}

Fig. 1: Identification of the interaction between SP and PF4 by QCM and DLS.
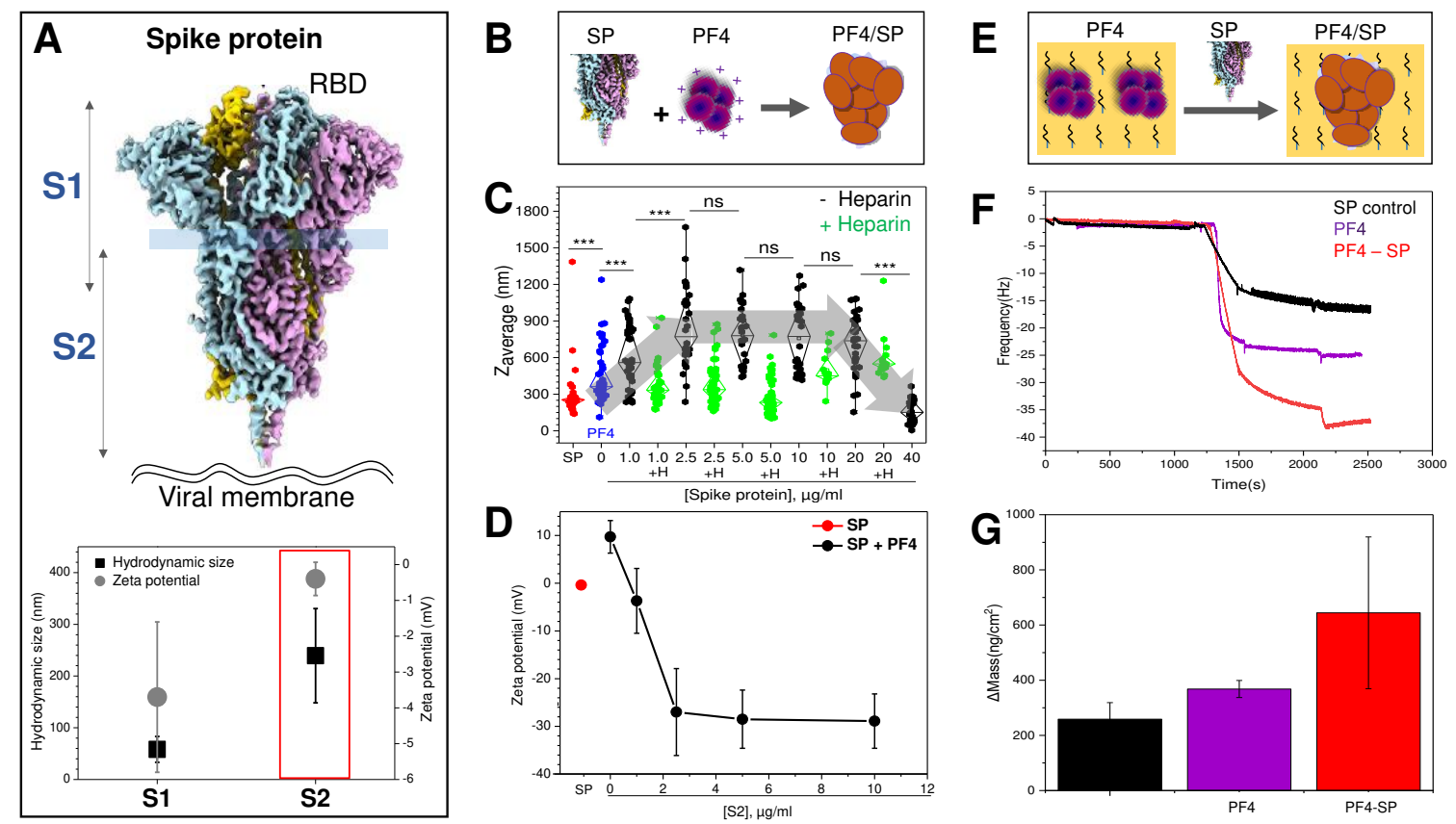

(A) Closed SARS-CoV-2 Spike protein trimer adapted from ${ }^{46}$ composes of $S_{1}$ and $S_{2}$ subsunits (top) that have different size and surface zetapotential (bottom). The $\mathrm{S}_{2}$ subsunit (red box) has a zeta potential $\sim$ zero while it is about $-5 \mathrm{mV}$ for the $S_{1}$ subsunit, indicating high tendency of forming aggregation of $\mathrm{S}_{2}$ subsunit. Thus, the $\mathrm{S}_{2}$ (named as $\mathrm{SP}$ ) is selected for further investigation. (B) Cartoon showing SP clusters PF4 (purple) and fuses energy to it, resulting in a conformational change in PF4 (orange) in DLS experiments. (C) Adding SP (red) to PF4 (blue, at $0 \mu \mathrm{g} / \mathrm{ml} \mathrm{SP}$ ), the size of the complex increased up to $2.5 \mu \mathrm{g} / \mathrm{ml} \mathrm{SP}$ and significantly reduced at $40 \mu \mathrm{g} / \mathrm{ml} \mathrm{SP}$ (black) ), whereas $0.2 \mathrm{U} / \mathrm{ml}$ heparin (green) significantly reduced the size of complexes. ANOVA test: $* * *=$ significant difference $(\mathrm{P}<0.05), \mathrm{ns}=$ no significant difference $(\mathrm{P}>0.05)$. (D) Zeta potential of SP is around zero (red), and of PF4 is $\sim 6 \mathrm{mV}$. Titration of SP to PF4, zeta potential switched to a negative value. $\mathrm{n}=3$ to 5 repetitions. (E) Cartoon showing immobilization of PF4 on a QCM chip via glutaraldehyde linkers (black) and pumping SP on the chip allows the formation of PF4/SP complexes. (F) QCM spectra show some minor frequency shift when (black) SP was added to the SAM layer for control, (purple) PF4 immobilized on the chip, and (red) SP bound to PF4 coated chip in which SP was added directly to the chip after measurement of PF4. (G) Highest mass change was induced by binding of SP with PF4. 
Fig. 2. Binding of SARS-CoV-2-SP to PF4 determined by SMFS and ELISA.

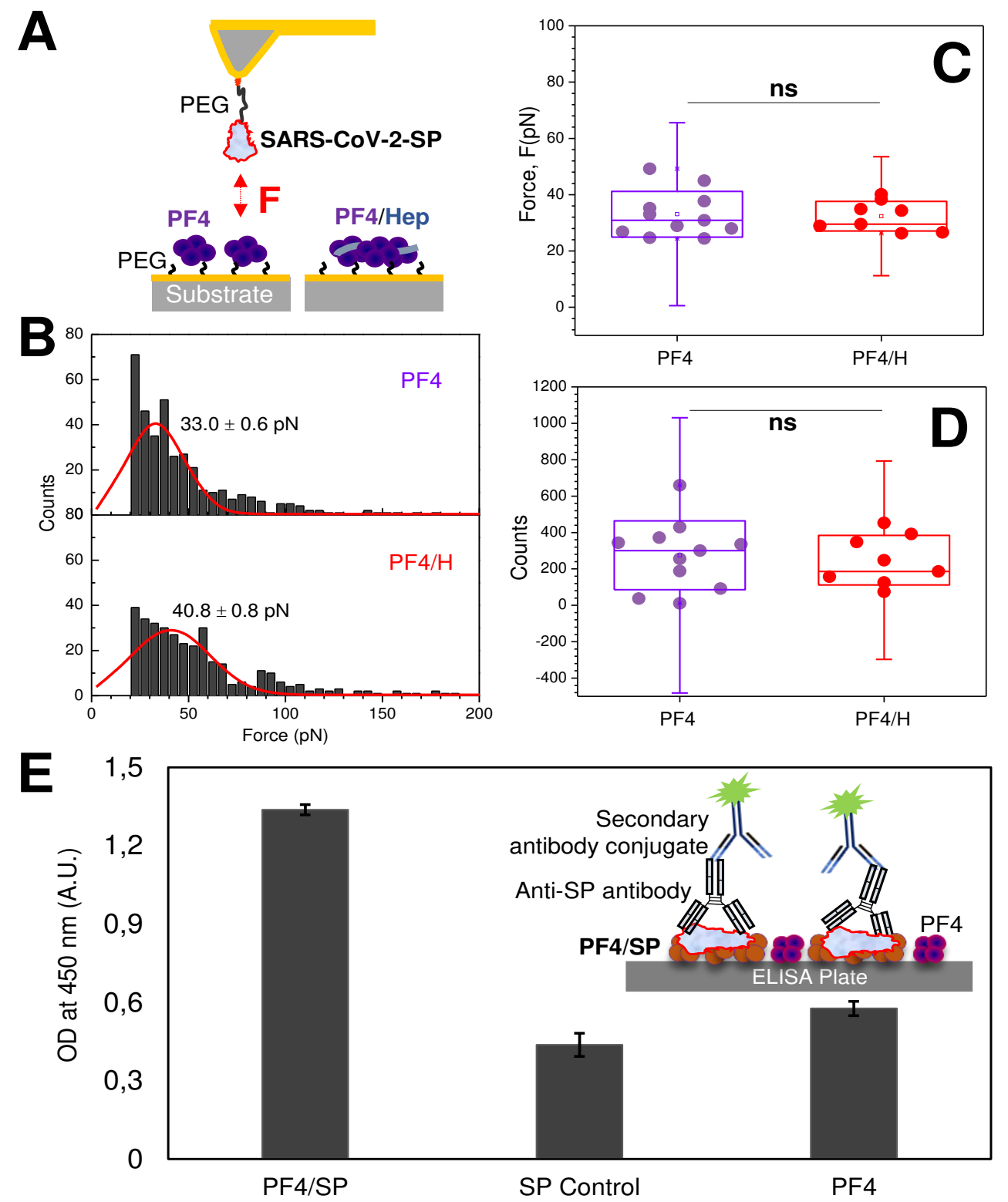

(A) Single -SP was attached covalently to a cantilever tip while the PF4 or preformed PF4/H complex was covalently immobilized on the substrate via PEG linkers. The binding force F was recorded when the tip approaches and then retracts from the substrate. (B) Typical histograms of force distribution followed single Gaussian fits that allowed the determination of average values and corresponding standard errors. (C) Quantification of data from different repetitions did not show a statistical difference in binding force and (D) frequency of interaction between PF4 and PF4/H complexes when interacting with SP. Each dot in (C, D) is average data obtained from an independent experiment at pulling speed $1 \mu \mathrm{m} / \mathrm{s}$. (E) Binding of SP to PF4 in ELISA: Cartoon shows ELISA set up for detection of binding of SP to PF4 immobilized on the plate (inset). SP binds to PF4 showing higher OD value than PF4 or SP alone. 
Fig. 3: SARS-CoV-2 SP induced platelet aggregation by CLSM.

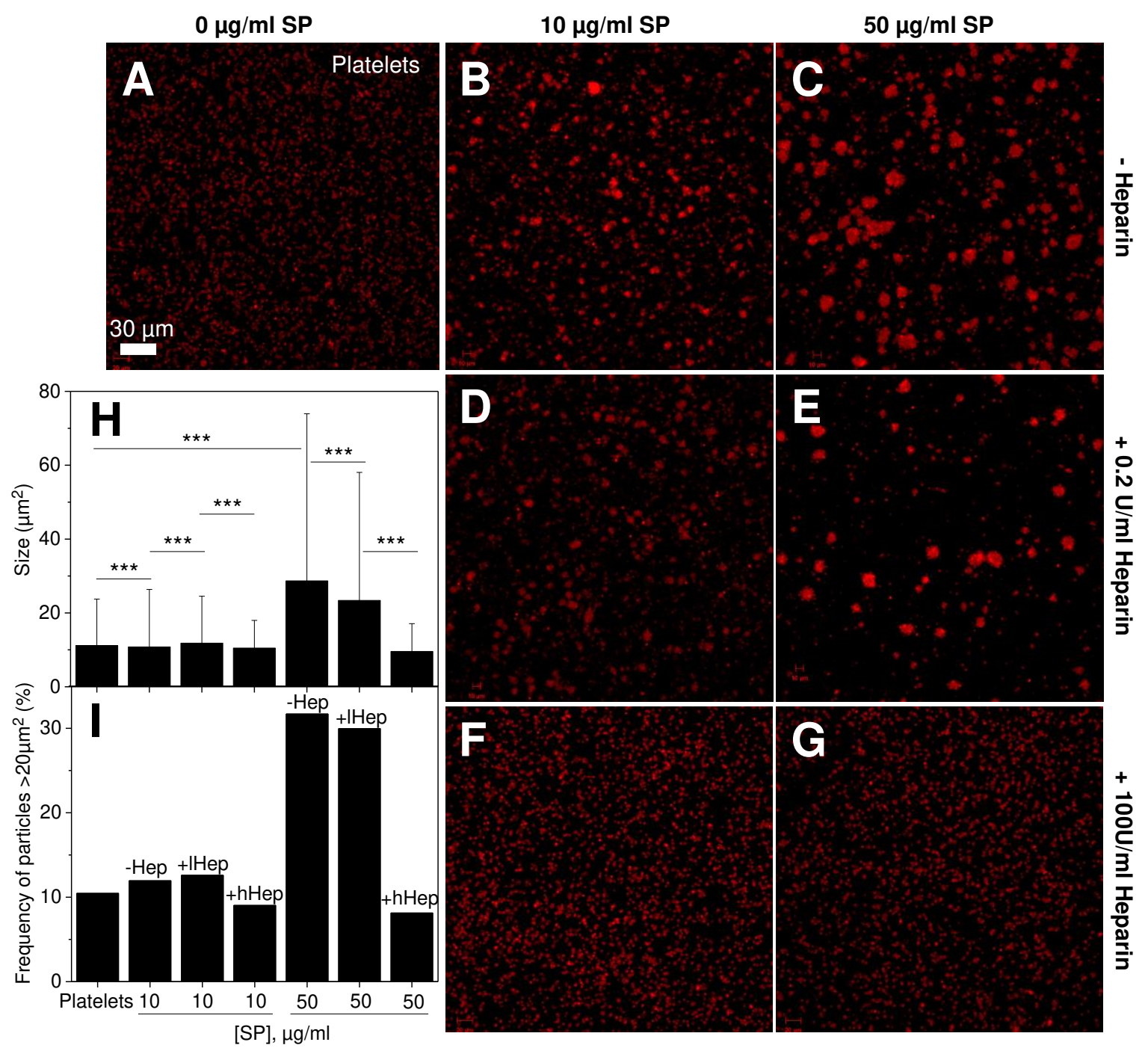

(A) Washed platelets alone ( $0 \mu \mathrm{g} / \mathrm{ml} \mathrm{SP}$, without heparin) did not aggregate. (B, C) In the absence of heparin, platelets aggregated at $10 \mu \mathrm{g} / \mathrm{ml}$ and strongly aggregated at $50 \mu \mathrm{g} / \mathrm{ml}$. (D, E) In the presence of $0.2 \mathrm{U} / \mathrm{ml}$ heparin, the degree of platelet aggregation slightly reduced compared to that in the absence of heparin. (F, G) In the presence of $100 \mathrm{U} / \mathrm{ml}$ heparin, SP did not induce platelet aggregation anymore. (H) Quantification of average sizes of all platelets showed that the largest size was observed at $50 \mu \mathrm{g} / \mathrm{ml} \mathrm{SP}$ while platelet sizes significantly differ among samples. (I) At size $>20 \mu \mathrm{m}^{2}, 50 \mu \mathrm{g} / \mathrm{ml}$ SP concentration caused a much higher number/frequency of large particles as compared to other conditions. The scale bar is $30 \mu \mathrm{m}$ for all images. $\mathrm{n}=3$ donors. ANOVA test: $* * *=$ significant difference $(\mathrm{P}<0.05), \mathrm{ns}=$ no significant difference $(\mathrm{P}>0.05)$. 
Fig. 4: Effect of PF4:SP concentration ratio on platelet aggregation at static condition.
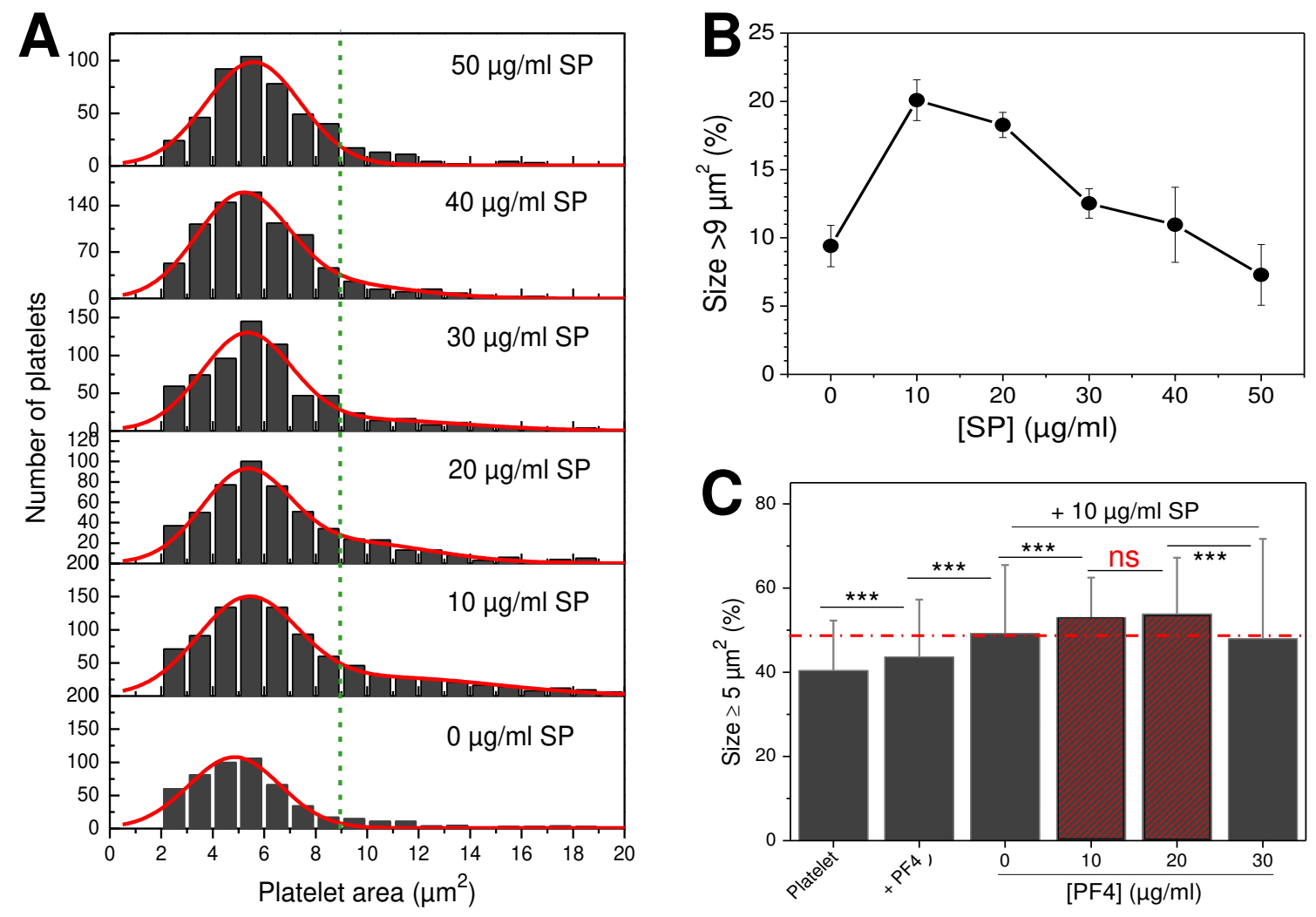

(A) Without adding PF4 to washed platelets, the size distribution of non-aggregated platelets with size $<9 \mu \mathrm{m}^{2}$ (left side of the green line) was almost identical at various SP concentrations while that of activated/aggregated platelets with size $>9 \mu \mathrm{m}^{2}$ was dissimilar. (B) the frequency of platelet activated/aggregated is highest at $10 \mu \mathrm{g} / \mathrm{ml} \mathrm{SP}$ and lower at higher SP concentration. (C) Adding PF4 into washed platelets in the presence of $10 \mu \mathrm{g} / \mathrm{ml} \mathrm{SP}$, maximal frequency of activated platelets at size $>5 \mu \mathrm{m}^{2}$ is observed between 10 and $20 \mu \mathrm{g} / \mathrm{ml} \mathrm{PF} 4$ (red bars) or at a PF4:SP molar ration between 3.1 and 6.2. $n=3$ repetitions from different platelet donors. ANOVA test: $* * *=$ significant difference $(\mathrm{P}<0.05), \mathrm{ns}=$ no significant difference $(\mathrm{P}>0.05)$. 
Fig. 5: Proposed mechanism of SARS-CoV-2-inducted platelet aggregation.

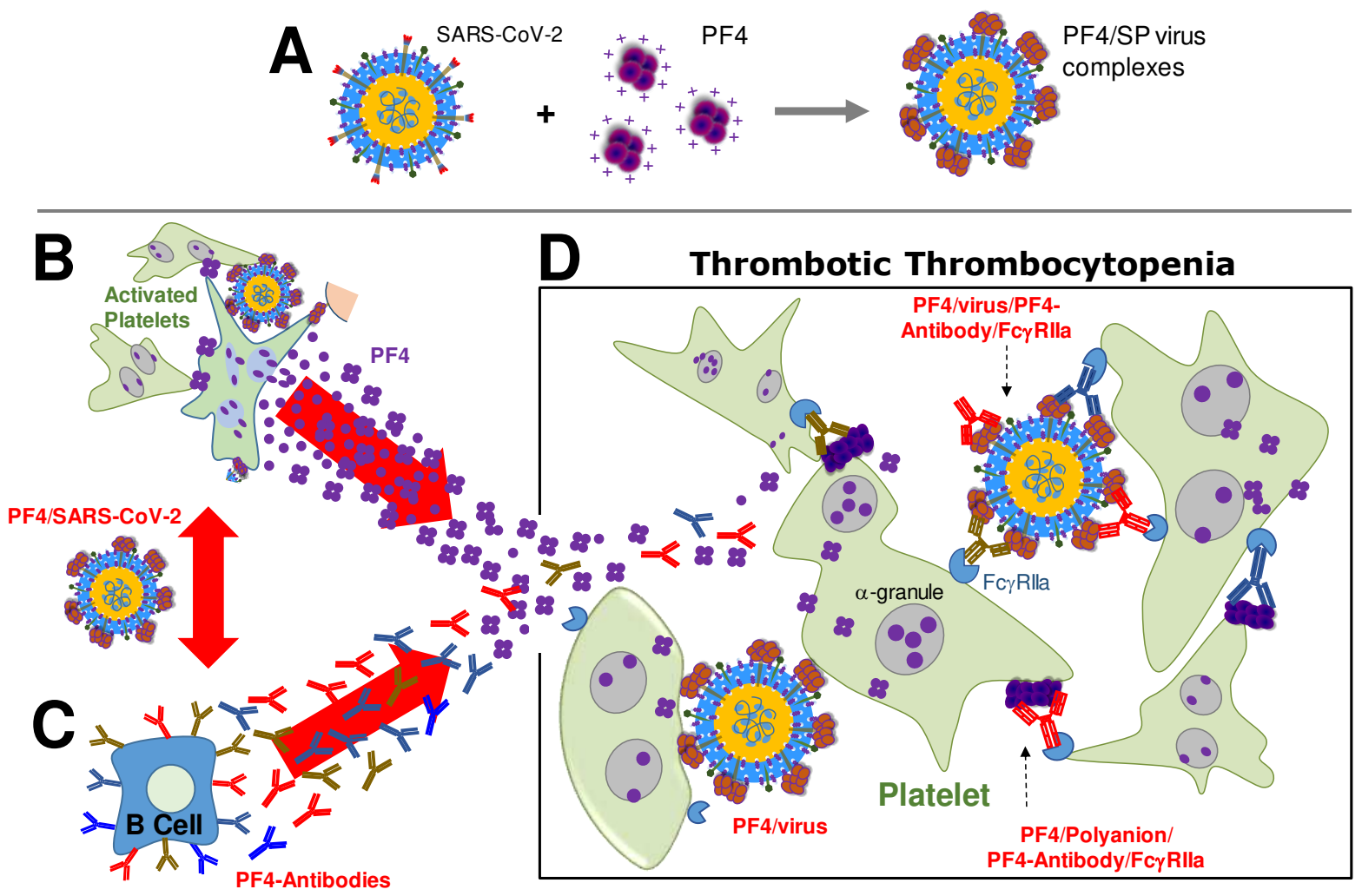

(A) Illustration showing SARS-Cov-2 clustering and fusing energy to PF4 molecules (emphasized by color changes in PF4) via SP, resulting in antigenic PF4/virus complexes that promote B-cells to produce PF4-antibodies. (B) The resulting complexes together with cell fragments adhere to and activate platelets that further release PF4. (C) The complexes then trigger immune B-cells to produce platelet-activating antibodies. (D) Formation of thrombotic thrombocytopenia: arrows point to the formed factors that cross-link platelets including PF4/virus, PF4/Polyanions-linked platelet-activating antibody via FcrRIIa, and PF4/virus-linked platelet-activating antibodies via FcrRIIa. 
Fig. 6: Proposed mechanism for vaccine-induced thrombotic thrombocytopenia (VITT).

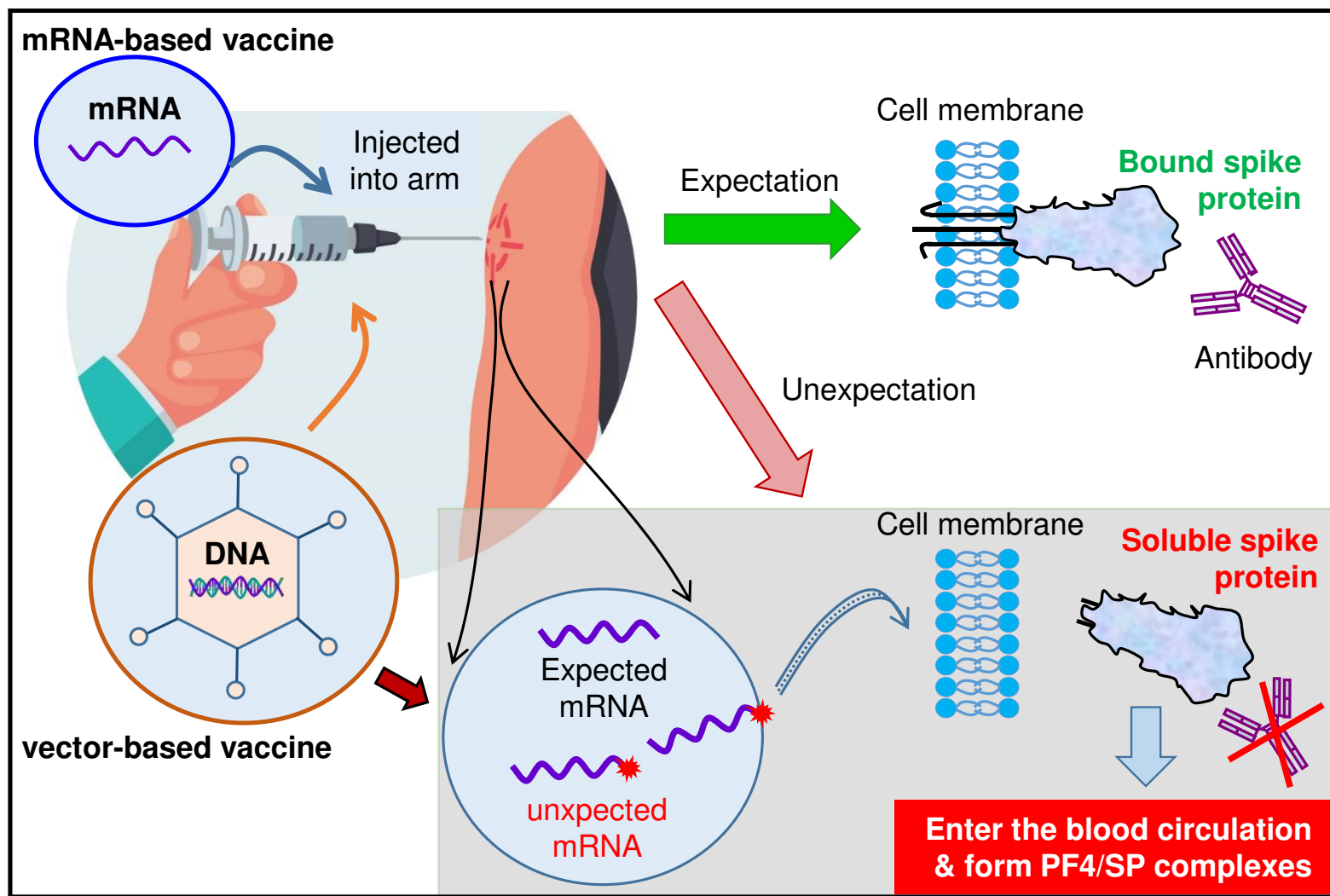

After being vaccinated with mRNA-based vaccine (blue circle) or vector-based vaccine (orange), spike proteins translated from cells will be transported to the cell plasma membrane for the production of anti-spike protein antibodies. However, an unexpect process during transcription of wildtype and codon-optimized spike open reading frames enables alternative splice events that lead to C-terminal truncated, soluble/partial spike proteins that do not contain nessessary part for adhering to cells as they should (gray rectangular). These soluble spike proteins can not trigger immune cells to produce anti-SP antibodies but they can then enter the blood circulation and form immunogenic complexes with PF4. 
Figure 7. Suggested additional consideration (blue circle) for diagnostic and therapeutic algorithm in patients with VITT to the guidance from the GTH (gray box).$^{59}$

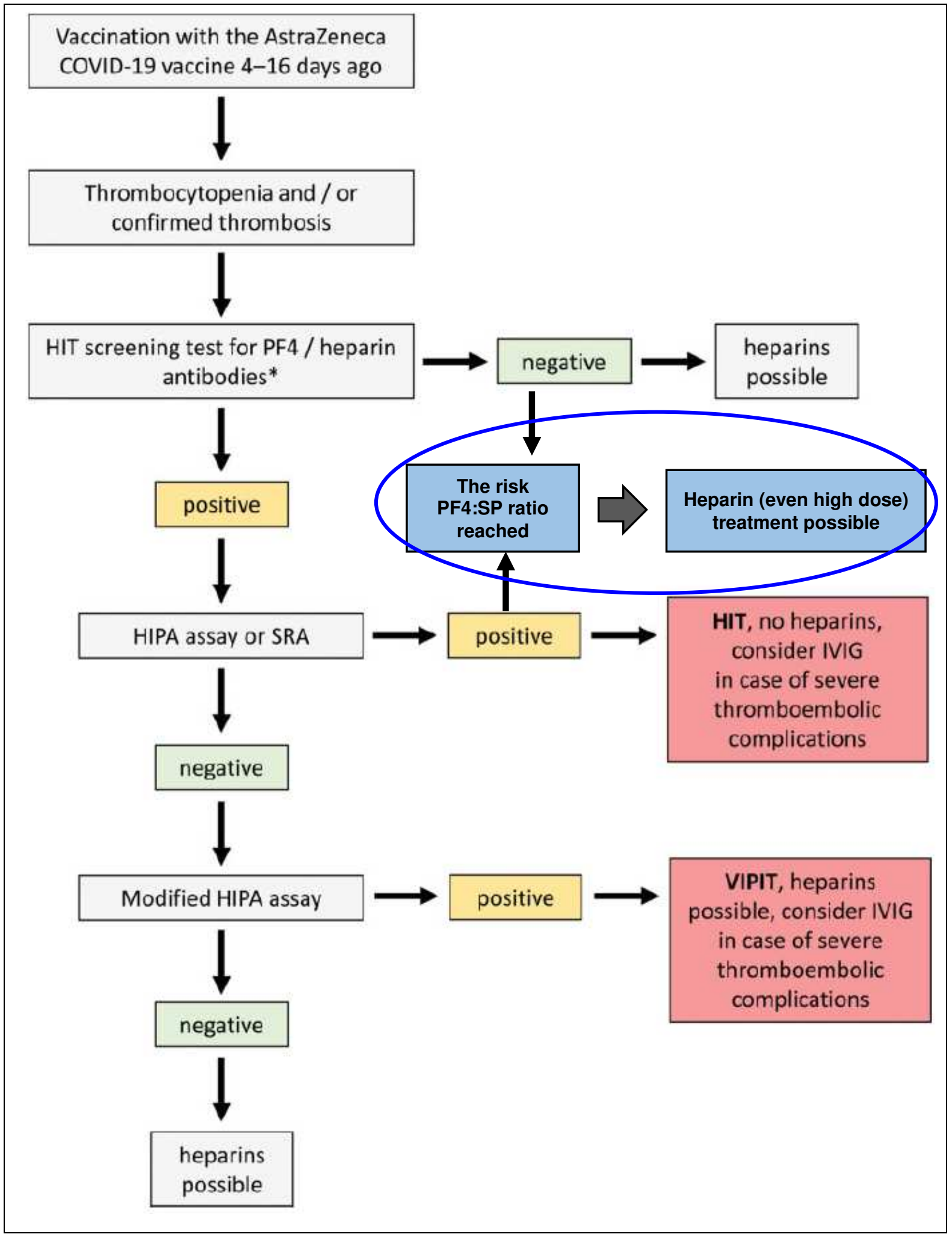

(blue) We recommend if serum is negative in screening test for HIT antibodies but positive in HIPA/SRA, the risk ratio of PF4:SP is reached, and therefore, heparin (even high dose heparin) treatment is possible. 


\section{Supplementary Information}

Supplementary Fig. 1: Effect of SARS-CoV-2-SP on the morphology of platelets incubated at $3^{\circ} \mathrm{C}$ without stirring imaged by CLSM.
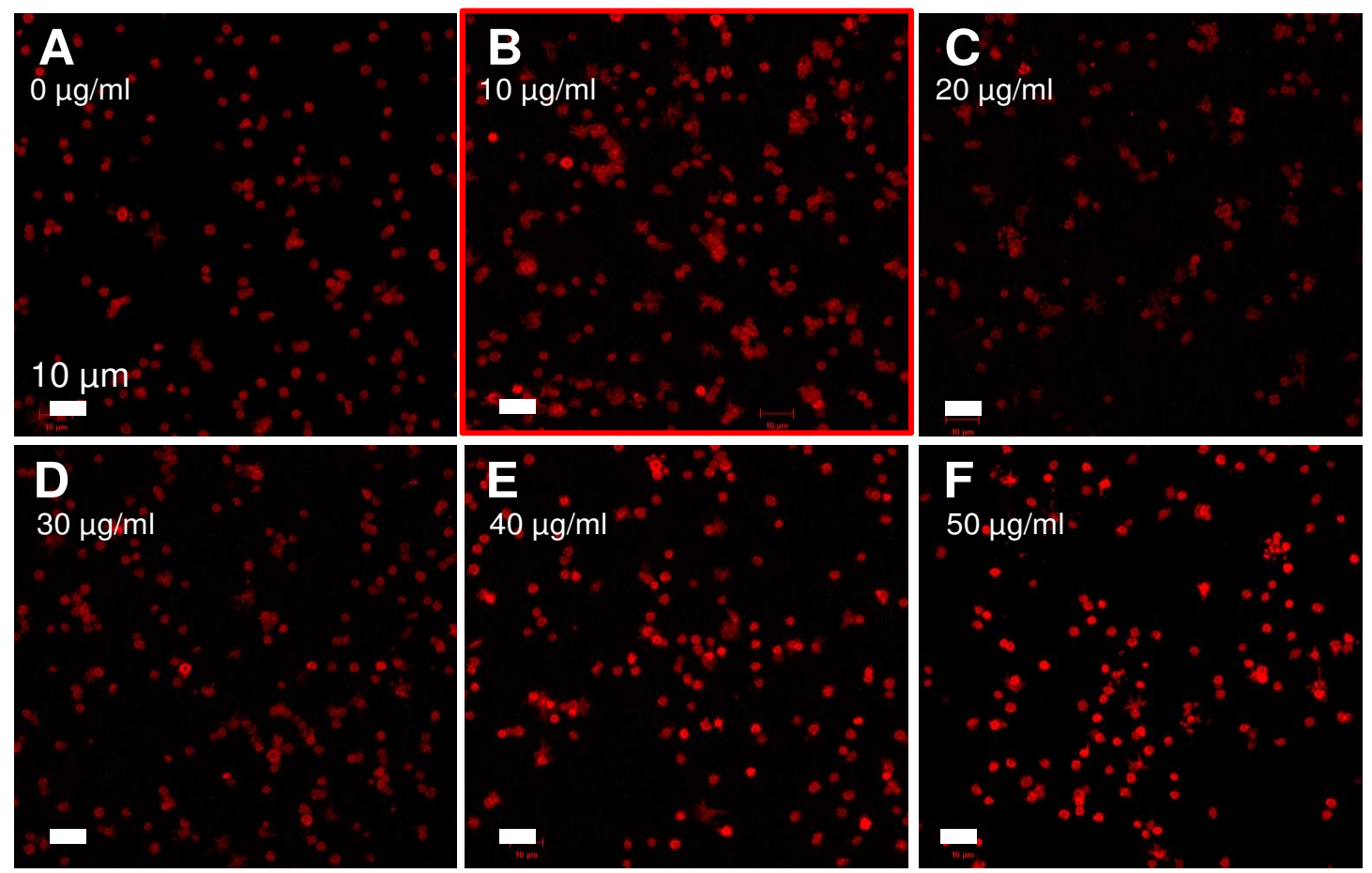

(A-F) Morphologies of platelets (red dots) in the presence of different concentrations of the SP show a stronger modification of platelet morphology at (red box) $10 \mu \mathrm{g} / \mathrm{ml}$. 
Supplementary Fig. 2: Identification of platelet activation caused by PF4-SP binding via analysis of CD62P using Flow cytometry.

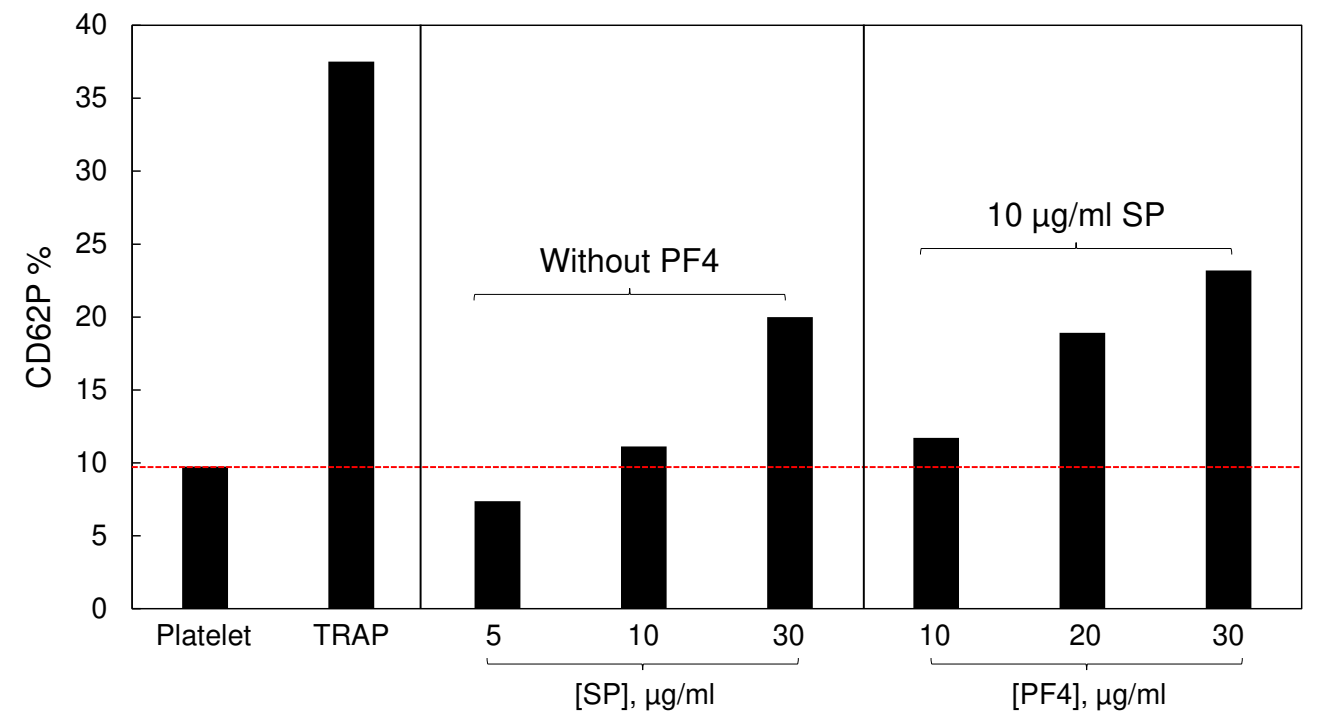

(left) TRAP as a positive control shows about $37 \%$ platelet activation while platelets alone as a negative show $<10 \%$ activation. (middle) SP without PF4 induced an increase of platelet activation at higher concentration and further enhanced activation in the presence of (right) PF4. 